\title{
Brain natriuretic peptide is stable in whole blood and can be measured using a simple rapid assay: implications for clinical practice
}

David R Murdoch, John Byrne, James J Morton, Theresa A McDonagh, Stephen D Robb, Suzanne Clements, Ian Ford, John J V McMurray, Henry J Dargie

Medical Research

Council's Clinical

Research Initiative in

Heart Failure,

University of Glasgow,

Glasgow, UK

D R Murdoch

J J Morton

T A McDonagh

$S$ D Robb

S Clements

J J V McMurray

H J Dargie

Department of

Cardiology, Western

Infirmary, Glasgow,

UK

D R Murdoch

J Byrne

T A McDonagh

J J V McMurray

H J Dargie

Robertson Centre for Biostatistics,

University of Glasgow,

Glasgow, UK

I Ford

Correspondence to:

Dr Murdoch, MRC Clinical

Research Initiative in Heart

Failure, West Medical

Building, University of

Glasgow, Glasgow G12 8QQ,

UK.

Accepted for publication 31 July 1997

\begin{abstract}
Objectives-To compare the stability of brain natriuretic peptide (BNP) to that of $\mathrm{N}$-terminal atrial natriuretic peptide (NTANP) in whole blood and plasma stored under different conditions. To compare a rapid, simple, direct (unextracted) BNP assay to a conventional assay using plasma extraction.
\end{abstract}

Design-Blinded, prospective, comparative study.

Setting-Tertiary referral cardiology department.

Subjects-Forty two subjects ( 24 men, 18 women) comprising 28 patients with left ventricular systolic dysfunction (LVSD) ranging from mild to severe and 14 healthy volunteers.

Main outcome measures-Stability of NTANP and BNP when stored as whole blood or plasma at room temperature over three days. Reproducibility of measurements.

Results-BNP was stable in whole blood stored at room temperature for three days; mean change in concentration $-7.4 \%$ (95\% CI 0.6 to -14.8$)$, (direct), $-6.3 \%$ (5.0 to -16.4$)$, (extracted); whereas a significant decline in BNP concentration was noted in plasma stored at room temperature; $-23.2 \%(-13.7$ to -31.6$)$, (direct); $-14.4 \% \quad(-3.2$ to -24.3$)$, (extracted). By contrast a small nonsignificant rise in NT-ANP concentration was noted both in whole blood and plasma stored at room temperature for three days; whole blood $+8.6 \%(+22.3$ to -3.5$)$, plasma $+6.3 \%$, $(23.2$ to -8.4$)$. The reproducibility of the BNP measurements, and particularly the rapid, direct, measurement, was superior to that for NT-ANP.

Conclusions-BNP is shown to be stable in whole blood for three days and can be measured using a rapid, simple assay. Routine assay of BNP is feasible in ordinary clinical practice and may be of value to general practitioners and hospital based physicians in the diagnosis and management of patients with LVSD. Samples can be sent to a central laboratory without special handling requirements.

(Heart 1997;78:594-597)

Keywords: brain natriuretic peptide; atrial natriuretic peptide; heart failure; diagnosis
Measurement of plasma atrial natriuretic peptide (ANP) or brain natriuretic peptide (BNP) concentration has been recognised as a potentially useful means of identifying patients with left ventricular systolic dysfunction (LVSD).$^{1-6}$ Measurement of ANP or BNP may thereby avoid the need for further cardiac investigations or target those investigations at patients most likely to have significant structural or functional heart disease. ${ }^{78} \mathrm{ANP}$ and BNP may also give useful prognostic information after acute myocardial infarction and in heart failure. $^{39-12}$ Natriuretic peptides may also be used to monitor the response to, and optimise, vasodilator and diuretic therapy in patients with LVSD. The widespread applicability of such a biochemical test is, however, dependent on its ease of use and, in particular, whether careful and complex sample handling is necessary-for example, collection of blood in chilled tubes, separation in a refrigerated centrifuge, and storage of plasma at $-70^{\circ} \mathrm{C}$. Such conditions are usually applied in research studies but are unrealistic in ordinary clinical practice. The feasibility of using natriuretic peptides in clinical practice also depends, to a lesser extent, on the availability of a simple assay (for example, using a direct, unextracted technique rather than an assay requiring plasma extraction) that can be carried out rapidly, and provide results quickly.

We describe the stability of NT-ANP and BNP under a number of different handling conditions. We report that BNP is sufficiently stable to make its use in routine clinical practice, including general practice, feasible. Furthermore, BNP can be measured, in unextracted plasma, using a rapid assay giving results within one day of collection.

\section{Methods}

SUBJECTS

Subjects expected to have plasma natriuretic peptide concentrations ranging from normal to high were studied. A total of 42 subjects were investigated (24 men, 18 women). These included nine patients with a recent myocardial infarction (five anterior, four inferior), four with stable heart failure resulting from LVSD caused by ischaemic heart disease, three with unstable angina, two after coronary angioplasty, two after permanent pacemaker insertion, two with rheumatic valvular disease, one after termination of supraventricular tachycardia, one with complete heart block (not paced), 
one with bacterial endocarditis, three patients with non-cardiac complaints without significant impairment of left ventricular systolic function, and 14 normal volunteers. The mean ages of the patients and the normal volunteers were 64.5 years (range 36-93) and 34.6 years (range 24-62), respectively.

\section{SAMPLE COLLECTION}

Blood was drawn from a forearm vein and divided directly into four chilled tubes containing EDTA $(1 \mathrm{mg} / \mathrm{ml}$ blood) and aprotinin (50 kIU/ml blood). The first sample was kept as whole blood at room temperature $\left(22^{\circ} \mathrm{C}\right)$ for 72 hours. The remaining three samples were separated in a refrigerated centrifuge. Two aliquots of plasma were frozen immediately to $-70^{\circ} \mathrm{C}$, and the final aliquot of plasma was stored at room temperature for 72 hours. Blood samples kept at room temperature were agitated twice daily to avoid separation and simulate postal transport. The whole blood samples were eventually separated after 72 hours and the plasma frozen to $-70^{\circ} \mathrm{C}$. Samples with visible evidence of haemolysis after separation $(\mathrm{n}=3)$ were discarded. No plasma samples were kept for more than 10 days (or less than seven days) at $-70^{\circ} \mathrm{C}$, before assay. The assays were performed in two batches with all samples from the same patient being analysed at the same time. Assays were performed blinded to patient identity, storage, collection, and handling conditions. Samples were thawed immediately before assay with determination of plasma NT-ANP and BNP being performed on the same plasma samples.

\section{NATRIURETIC PEPTIDE MEASUREMENT}

Brain natriuretic peptide was assayed without prior extraction of plasma using a direct, specific, monoclonal antibody radioimmunoassay kit supplied by Shionogi (Settsu-shi, Osaka, Japan). ${ }^{13}$ NT-ANP (1-30) and BNP were also assayed by radioimmunoassay after extraction from acidified plasma using C18 reverse phase columns (Sep-Pak, Waters Associates Ltd) using a modification of a previously described method. ${ }^{14}$ A Peninsula Laboratories antibody, RAS 9129, (Belmont, California, USA) was used for NT-ANP, and a Peninsula Laboratories kit for BNP. All samples were run in duplicate and the average of the two measurements reported. The between assay

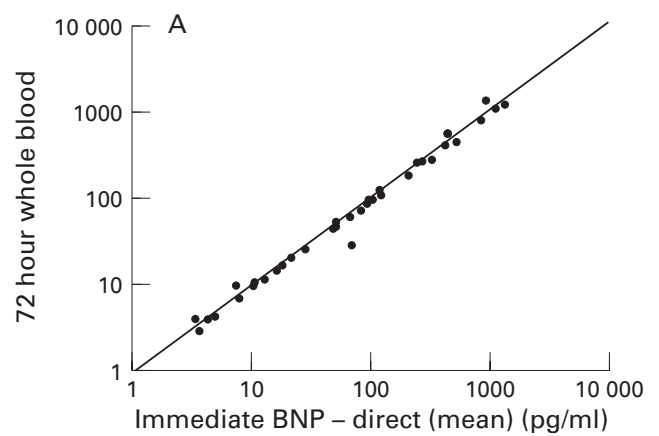

coefficients of variation were $15 \%$ for the NT-ANP extraction assay and $16 \%$ for the BNP extraction assay.

\section{STATISTICAL ANALYSIS}

Because of their skewed distributions, all analyses on BNP and NT-ANP concentrations were carried out on the logarithmically transformed data. The average results for the two aliquots frozen immediately were used for comparison with the data for samples stored at room temperature. Differences among the various approaches for handling the samples before storage were assessed by paired $t$ tests and corresponding 95\% confidence intervals. To aid interpretation, these confidence intervals on a logarithmic scale were transformed into percentage differences. Comparisons between groups were based on two sample $t$ tests. The reproducibility of the assays was assessed using the paired samples frozen immediately. The sample variance between samples within subjects is expressed as a percentage of the sample variance of the measurement between subjects.

\section{Results}

RANGE OF PLASMA NATRIURETIC PEPTIDE CONCENTRATIONS

Plasma BNP concentrations ranged from 3.1 to $1375.9 \mathrm{pg} / \mathrm{ml}$ (mean 262.9), using the direct assay and from 6.6 to $492.8 \mathrm{pg} / \mathrm{ml}$ (mean 92.8 ), using the extraction assay.

NT-ANP concentrations ranged from 0.7 to $15.9 \mathrm{ng} / \mathrm{ml}$ (mean 4.5) after extraction.

\section{REPRODUCIBILITY OF ASSAYS}

The variance of measurements between aliquots from the same subject, expressed as a percentage of the variance between subjects was $0.1 \%, 3.0 \%$, and $6.0 \%$ for directly measured BNP, extracted BNP, and NT-ANP respectively. The reproducibility of all measurements was good, with BNP measurements, and particularly the direct measurement, being more reproducible than those for NT-ANP.

\section{STABILITY OF NATRIURETIC PEPTIDES}

Brain natriuretic peptide

Only a minor non-significant decline in BNP concentration was noted between samples processed conventionally by immediate separation and freezing, and those stored in whole

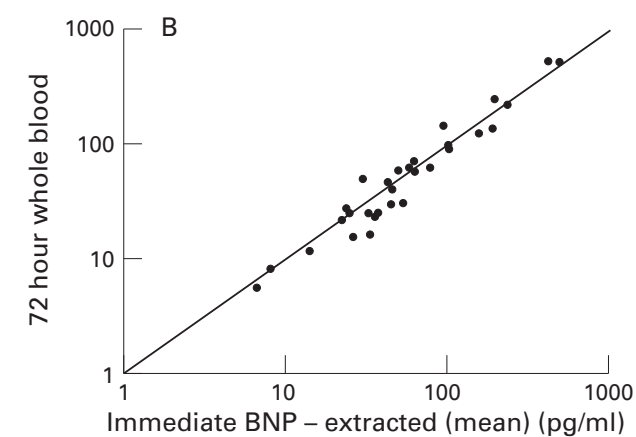

Figure 1 Brain natriuretic peptide concentration (log), measured by the direct $(A)$ and extracted (B) assays in plasma separated and stored immediately at $-70^{\circ} \mathrm{C}$, or kept for 72 hours as whole blood at room temperature. Line of identity is shown. 

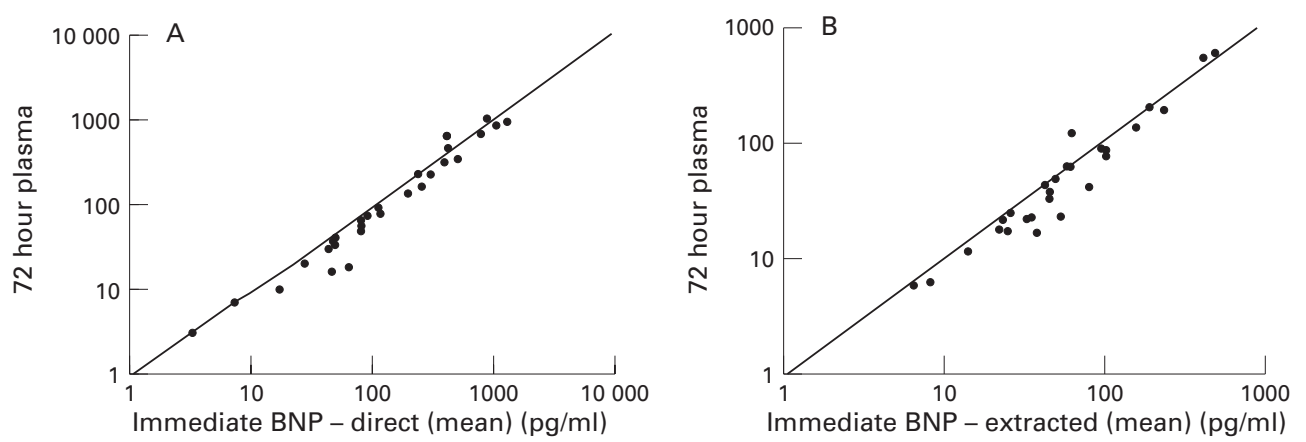

Figure 2 Brain natriuretic peptide concentration (log), measured by the direct $(A)$ and extracted (B) assays respectively, in plasma separated and stored immediately at $-70^{\circ} \mathrm{C}$, or kept for 72 hours as plasma at room temperature. Line of $i d e n t i t y$ is shown.
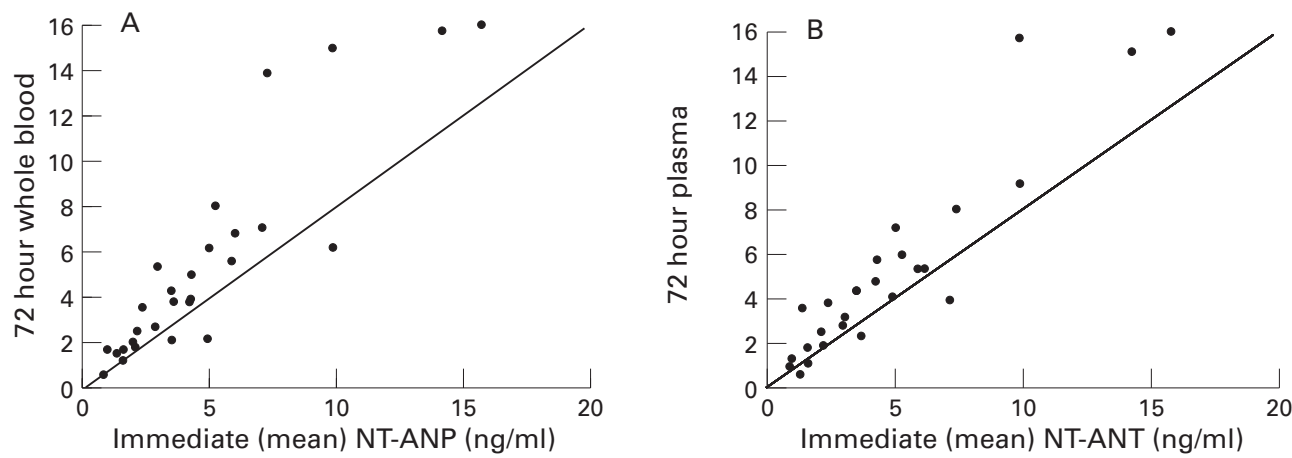

Figure $3 N$-terminal atrial natriuretic peptide concentration in plasma separated and stored immediately at $-70^{\circ} \mathrm{C}$, or kept for 72 hours as whole blood $(A)$ and 72 hours as plasma $(B)$ at room temperature. Line of identity is shown.

blood at room temperature for three days; mean change in concentration; $-7.4 \%(95 \%$ CI -14.8 to 0.6$) \mathrm{p}=0.07$ (direct), $-6.3 \%$ $(-16.4$ to 5.0$) \mathrm{p}=0.25$ (extracted). This was consistent throughout the range of plasma BNP concentrations (fig 1). For samples with low baseline BNP concentration, no rise in concentration was demonstrated.

A more pronounced decline in BNP concentration was noted with storage of samples as plasma, as compared with whole blood, at room temperature for 72 hours, which was significant for samples processed by both techniques. The mean change in concentration was $-23.2 \%(-31.6$ to -13.7$) \mathrm{p}=0.0004$ with the direct assay, and $-14.4 \%(-24.3$ to -3.2$)$ $\mathrm{p}=0.015$ with the extracted assay. This was an unexpected but consistent finding of all samples (fig 2).

\section{$N$-terminal atrial natriuretic peptide}

A small non-significant rise in NT-ANP was noted in whole blood, at room temperature, over a three day period; mean change in peptide concentration; $+8.6 \%$ ( -3.5 to 22.3 ) $\mathrm{p}=0.16$, (fig $3 \mathrm{~A})$. This was similar in samples stored as plasma over the same time period; mean change in peptide $+6.3 \%$ ( -8.4 to 23.2$)$ $\mathrm{p}=0.40$, (fig 3B).

\section{Discussion}

This study confirms previous findings that NT-ANP is reasonably stable in whole blood at room temperature over a period of days. ${ }^{15}$ More importantly it shows, for the first time, that BNP is stable for 72 hours. This finding is critical because stability over time is a pre-requisite for the use of BNP in a clinical setting. It is also important because of the potential superiority of BNP over ANP or NT-ANP as a marker of LVSD. ${ }^{512} 16-19$ The potential of BNP as a clinical tool is even greater because of the finding that the simpler and faster direct assay for BNP performed at least as well as the assay requiring plasma extraction. Specifically, we have established that BNP has the biochemical properties that would enable it to be used in ordinary clinical practice, by both general practitioners and hospital based physicians, for diagnostic assessment of patients with LVSD. In this context, by daily agitation of samples to simulate postal transport, we have confirmed that the stability of BNP would be sufficient to allow for blood samples collected in the community to be sent to a central laboratory by mail. For example, BNP might be measured, in this way, in patients suspected of having heart failure in primary care, most of whom will not have significant structural heart disease. ${ }^{20}{ }^{21}$ Only those patients with an increased BNP concentration would then go on to have echocardiography. Such an approach has the potential to greatly reduce the number of unnecessary echocardiographies performed.

One curious and unexplained finding in this study was the significant decline in BNP concentration noted in plasma, compared with whole blood, at room temperature for three days. This finding suggests that the simpler option of collecting and storing or posting whole blood is preferable to separating plasma. In summary we have shown that BNP is stable 
in whole blood and can be reliably measured using a simple, rapid assay. BNP could feasibly be used in ordinary clinical practice.

David R Murdoch, James J Morton, Theresa A McDonagh, John J V McMurray, and Henry J Dargie are supported by The Medical Research Council (MRC). We thank Dr A David Cunningham BSc PhD, Computer Services Manager, MRC Clinical Research Initiative in Heart Failure, for assistance with data analysis and Merck Inc for the funding of the direct brain natriuretic peptide (Shionogi) assay kits.

1 Mukoyama M, Nakao K, Saito Y, et al. Increased human brain natriuretic peptide in congestive heart failure. $N E n g$ f Med 1990;323:757-8.

2 Lerman A, Gibbons RJ, Rodeheffer RJ, et al. Circulating $\mathrm{N}$-terminal atrial natriuretic peptide as a marker for symptomless left-ventricular dysfunction. Lancet 1993;341: tomless

3 Darbar D, Davidson NC, Gillespie N, et al. Diagnosticvalue of b-type natriuretic peptide concentrations in patients with acute myocardial-infarction. Am f Cardio

4 Davis M, Espiner E, Richards G, et al. Plasma brain natriuretic peptide in assessment of acute dyspnoea. Lancet 1994 343:440-4.

5 Motwani JG, McAlpine H, Kennedy N, Struthers AD. Plasma brain natriuretic peptide as an indicator for angiotensin-converting-enzyme inhibition after myocardial infarction. Lancet 1993;341:1109-13.

6 Struthers AD. Prospects for using a blood sample in the diagnosis of heart failure. $O 7 \mathrm{Med}$ 1995;88:303-6.

7 Struthers AD. Plasma concentrations of brain natriuretic peptide: will this new test reduce the need for cardiac investigations? Br Heart f 1993;70:397-8.

8 Struthers AD. 10 years of natriuretic peptide research-a new dawn for their diagnostic and therapeutic use. $B M^{\prime}$ new dawn for their

9 Gottlieb SS, Kukin ML, Ahern D, Packer M. Prognostic importance of atrial natriuretic peptide in patients with importance of atrial natriuretic peptide in patients with
chronic heart failure. $\mathcal{f} \mathrm{Am}$ Coll Cardiol 1989;13:1534-9.

10 Swedberg K, Eneroth P, Kjekshus J, Wilhelmsen L. Hormones regulating cardiovascular function in patients with severe congestive heart failure and their relation to mortality. CONSENSUS Trial Study Group. Circulation $1990 ; 82: 1730-6$.

11 Hall C, Rouleau JL, Moye L, et al. N-terminal proatrial natriuretic factor. An independent predictor of long-term prognosis after myocardial infarction. Circulation 1994;89: 1934-42.

12 Arakawa N, Nakamura M, Aoki H, Hiramori K. Plasma brain natriuretic peptide concentrations predict survival after acute myocard$$
\text { 1996:27:1656-61. }
$$

13 Kono M, Yamauchi A, Tsuji T, et al. An immunoradiometric assay for brain natriuretic peptide in human plasma. Kaku Igaku Gijutsu 1993;13:2-7.

14 Richards AM, Tonolo G, McIntyre GD, Leckie BJ, Robertson JI. Radio-immunoassay for plasma alpha human atrial natriuretic peptide: a comparison of direct and preextracted methods. F Hypertens 1987;5:227-36.

15 Cleland JGF, Ward S, Dutka D, Habib F, Impallomeni M, Morton JJ. Stability of plasma concentrations of $n$-terminal and c-terminal atrial natriuretic peptides at roomtemperature. Heart 1996;75:410-13.

16 Choy AM, Darbar D, Lang CC, et al. Detection of left ventricular dysfunction after acute myocardial infarction: comparison of clinical, echocardiographic, and neurohormonal methods. Br Heart $\mathcal{F}$ 1994;72:16-22.

17 Davidson NC, Naas AA, Hanson JK, Kennedy NSJ, Coutie WJ, Struthers AD. Comparison of atrial natriuretic peptide, b-type natriuretic peptide, and n-terminal proatrial natriuretic peptide as indicators of left ventricular prop 7 as in 199677:828-31.

18 Yamamoto K, Burnett JC, Jougasaki M, et al. Superiority of brain natriuretic peptide as a hormonal marker of ventricular systolic and diastolic dysfunction and ventricular hypertrophy. Hypertension 1996;28:988-94.

19 Omland T, Aakvaag A, Vik-Mo H. Plasma cardiac natriuretic peptide determination as a screening test for the detection of patients with mild left ventricular impairment. Heart 1996;76:232-7.

20 Wheeldon NM, MacDonald TM, Flucker CJ, McKendrick AD, McDevitt DG, Struthers AD. Echocardiography in chronic heart failure in the community. $O \mathcal{F}$ Med 1993;86: $17-23$.

21 Francis CM, Caruana L, Kearney P, et al. Open access echocardiography in management of heart-failure in the community. BMF 1995;310:634-6. 